\title{
Syntax in Action Has Priority over Movement Selection in Piano Playing: An ERP Study
}

\author{
Roberta Bianco ${ }^{1}$, Giacomo Novembre ${ }^{2}$, Peter E. Keller ${ }^{2}$, Florian Scharf ${ }^{1}$, \\ Angela D. Friederici ${ }^{1}$, Arno Villringer ${ }^{1}$, and Daniela Sammler ${ }^{1}$
}

\begin{abstract}
Complex human behavior is hierarchically organized. Whether or not syntax plays a role in this organization is currently under debate. The present ERP study uses piano performance to isolate syntactic operations in action planning and to demonstrate their priority over nonsyntactic levels of movement selection. Expert pianists were asked to execute chord progressions on a mute keyboard by copying the posture of a performing model hand shown in sequences of photos. We manipulated the final chord of each sequence in terms of Syntax (congruent/incongruent keys) and Manner (conventional/ unconventional fingering), as well as the strength of its predictability by varying the length of the Context (five-chord/two-
\end{abstract}

\section{INTRODUCTION}

To facilitate everyday interactions and communication, the brain constantly screens the environment for regularities, forms predictions about upcoming events, and accordingly "pre-engages" potentially relevant neural or cognitive processes (Tenenbaum, Kemp, Griffiths, \& Goodman, 2011; Bubic, von Cramon, \& Schubotz, 2010; Wilson \& Knoblich, 2005). This ability, which does not require deliberate effort or awareness, might be a general function shared by different cognitive domains and pivotal for survival (Perruchet \& Pacton, 2006).

Understanding how simple elements are planned and perceived in temporally ordered and coherently structured sequences constitutes a central question in comparative studies across music, language, and action domains (Fitch \& Martins, 2014; Tillmann, 2012). The specifically human ability of the brain to variably combine discrete meaningful units into rule-based hierarchical sequences is what is referred to as "syntactic processing" and has been defined as core aspect of language and communication (Friederici, 2011; Hauser, Chomsky, \& Fitch, 2002; Lashley, 1951). Over the past years, similarities in the syntactic organization of language and Western music have been increasingly demonstrated (Rohrmeier

\footnotetext{
${ }^{1}$ Max Planck Institute for Human Cognitive and Brain Sciences, Leipzig, Germany, ${ }^{2}$ Western Sydney University, Sydney, Australia

chord progressions). The production of syntactically incongruent compared to congruent chords showed a response delay that was larger in the long compared to the short context. This behavioral effect was accompanied by a centroparietal negativity in the long but not in the short context, suggesting that a syntax-based motor plan was prepared ahead. Conversely, the execution of the unconventional manner was not delayed as a function of Context and elicited an opposite electrophysiological pattern (a posterior positivity). The current data support the hypothesis that motor plans operate at the level of musical syntax and are incrementally translated to lower levels of movement selection.
\& Koelsch, 2012; Katz \& Pesetsky, 2011; Koelsch, 2005; Patel, 2003). Experimental studies have shown similar neural correlates for syntactic operations in language and music perception (Patel, Gibson, Ratner, Besson, \& Holcomb, 1998; Sammler, Koelsch, \& Friederici, 2011; Fedorenko, Patel, Casasanto, Winawer, \& Gibson, 2009; Koelsch, Gunter, Wittfoth, \& Sammler, 2005; Maess, Koelsch, Gunter, \& Friederici, 2001) and also in the processing of complex action (Clerget, Winderickx, Fadiga, \& Olivier, 2009; Fazio et al., 2009) inviting the hypothesis that syntactic processing might be a general "supramodal" key capability of the human brain (Fadiga, Craighero, \& D’Ausilio, 2009; Slevc, Rosenberg, \& Patel, 2009; Patel, 2003). Although analogies with the domain of action, in terms of hierarchical and combinatorial organization (Pulvermüller, 2014; Guerra-Filho \& Aloimonos, 2012; Pastra \& Aloimonos, 2012; Pulvermüller \& Fadiga, 2010) remain conceptually controversial, they might be empirically tenable if shifted from actions to action planning (Moro, 2014a, 2014b). Therefore, in this study, we aimed to explore syntax-related mechanisms operating during action motor planning.

Piano performance in the Western classical music tradition provides an ideal test bed for exploring syntax in the action domain. First, playing chord progressions from this tradition is the direct motoric translation of musical syntax, a theoretically established hierarchical system of rules governing music structure (Rohrmeier, 2011). Second, it affords the possibility to investigate different hierarchical 
stages in action planning (Keller, 2012; Uithol, van Rooij, Bekkering, \& Haselager, 2012; Haggard, 2008; Shaffer, 1981) from lower nonsyntactic levels of movement selection to higher levels of syntax-based action plans.

Sammler, Novembre, et al. (2013) and Novembre and Keller (2011) showed that expert pianists_-due to intense practice-have motorically learned syntactic regularities governing musical sequences and therefore generate motor predictions based on their acquired long-term syntactic knowledge. In a priming paradigm, expert pianists were asked to imitate silent videos of a handplaying chord sequences. The last chord was either syntactically congruent or incongruent with the preceding musical context. Despite the absence of musical sounds, both studies revealed slower imitation times for syntactically incongruent chords as well as motor facilitation (i.e., faster responses) for the syntactically congruent chords. In terms of ERPs (Sammler, Novembre, Koelsch, \& Keller, 2013), the imitation of the incongruent chords elicited an early negativity, which was associated with the perception of the syntactic violation (Koelsch, 2009), and a later posterior negativity, indexing the reprogramming (Leuthold \& Jentzsch, 2002) of an anticipated motor act (i.e., the congruent chord) primed by the syntactic structure of the musical sequence. In line with models of incremental planning of serial actions (Palmer \& Pfordresher, 2003), the authors argued that, during imitation of musical sequences, motor predictions of trained musicians are strongly based on long-term music-syntactic knowledge, as abstract structuring principles translate into a "grammar of musical action."

However, piano performance not only requires the planning of which chord to play according to the preceding music-syntactic context but also the selection of a specific fingering for an optimal and smooth execution of the musical sequence. Notably, through intensive musical training, frequently occurring musical patterns (i.e., scales, chord progressions) are associated with conventional fingering configurations that are automatically activated during execution of these patterns (Gellrich \& Parncutt, 1998; Sloboda, Clarke, Parncutt, \& Raekallio, 1998; Clarke, Parncutt, Raekallio, \& Sloboda, 1997). From this perspective, it may be suggested that motor pattern familiarity, beyond syntactic knowledge, has a role in motor predictions when playing common chord progressions. This assumption finds support in the facilitated imitation of overlearned (Koeneke, Lutz, Herwig, Ziemann, \& Jäncke, 2006; Hund-Georgiadis \& von Cramon, 1999) and complex actions that belong to one's motor repertoire (Aglioti, Cesari, Romani, \& Urgesi, 2008; Calvo-Merino, Glaser, Grèzes, Passingham, \& Haggard, 2005). To what extent action planning operates at the level of musical syntax or at the level of common transitions of fingering configurations (i.e., the manner) is addressed here.

In the present ERP study, we aimed at untangling two hierarchical stages of musical action planning related to (i) selecting a syntax-based motor program (relative to the musical goal) versus (ii) setting the parameters of this program (the specific movement selection defining the manner of execution). Evidence for the dissociation between program selection and parameter setting has been gleaned from theoretical and empirical work. For example, the framework of "generalized motor programs" (Rosenbaum, Kenny, \& Derr, 1983; Keele \& Summers, 1976; Schmidt, 1975; Lashley, 1951) posits that action plans consist of core motor programs whose specific movement parameters are only chosen at the time of their use. Furthermore, it has been shown that the performance of advanced pianists is based on abstract conceptual plans and is independent of the specific movement requirements (Palmer \& Meyer, 2000). Similarly, a dissociation between a more general and higher versus a more specific and lower level of action processing finds support in the "hierarchical organization of goal-directed actions" theory (see Grafton, 2009). Along these lines, the priority of the goal of an action over the means used to achieve it has been extensively demonstrated in behavioral imitation (Wohlschläger, Gattis, \& Bekkering, 2003; Bekkering, Wohlschläger, \& Gattis, 2000), neuroimaging (Hamilton \& Grafton, 2006; Chaminade, Meltzoff, \& Decety, 2002; Koski et al., 2002), and brain stimulation studies (Lago \& Fernandez-del-Olmo, 2011; Cattaneo, Caruana, Jezzini, \& Rizzolatti, 2009). Therefore, we transferred this hierarchical concept of action planning to music by focusing on predictions at the two levels of the motor hierarchy (goal and manner; see also Novembre \& Keller, 2011). We reasoned that motor predictions of expert pianists should concern the musical goal (Syntax) rather than the finger movement selection (Manner), which should be specified only at the time of execution.

We asked expert pianists to watch and execute as fast and accurately as possible chord sequences played by a performing pianist's hand presented in a series of photos on a computer screen. Moreover, to negate exogenously driven auditory predictive processes, no sound was used. Piano performance (RTs and errors) and an EEG were recorded. In a $2 \times 2$ factorial design, we manipulated the last chord of the sequences in terms of the identity of the target keys (Syntax congruent/incongruent) to address the syntactic level of action planning and in terms of fingering (Manner correct/incorrect) to address the level of movement selection. To induce different strengths of syntax/manner-based predictions, pianists were presented with five-chord or two-chord sequences (long/short Context). The execution of the long compared to the short context was expected to provide more information, hence lead to a stronger prediction of the last chord to be executed. Crucially, the manipulation of the manner, while keeping the syntax congruent and vice versa, allowed us to dissociate behavioral and neural patterns elicited by the execution of the syntactic violation (Syntax) from those triggered by a general violation of movement patterns (Manner). Additionally, the $2 \times 2$ factorial design permitted us to investigate syntax-related 
mechanisms on top of the concurrent manner violation to test whether, in musical action planning, high levels of syntactic operations are prioritized over movement parameter specification.

First, we hypothesized that motor predictions in expert pianists are driven by music-syntactic knowledge more than by motor pattern familiarity. This should be reflected in a stronger priming effect of the long context on the musical goal (Syntax) than and irrespective of the specific movement selection (Manner). Specifically, we expected the execution of the syntactically congruent/ incongruent chords to be facilitated/impeded more strongly in the long than in the short contexts, whereas no such effect should occur during the execution of the manner correct/incorrect chords. Second, in terms of neural correlates, we predicted specific response-related patterns evoked by the syntax violation, different from those associated with the processing of the manner violation. To this end, we specifically focused on the syntax-related early and late negativity described by Sammler, Novembre, et al. (2013) and manner-related effects in the same time windows.

\section{METHODS}

\section{Participants}

Twenty-six pianists (16 women) aged $20-33$ years (mean $=$ 25.15; $S D=3.55$ ) were included in the analysis. Eight more pianists were tested but excluded because of an insufficient number of valid trials (cutoff $=50 \%$ of valid trials). The included pianists possessed between 12 and 27 years of classical music training (mean years of training $=18.21 ; S D=3.92$ ) and had started to play the piano on average at 6.04 years $(S D=2.73)$. All participants were naive with regard to the purpose of the study. They gave written informed consent to take part in this experiment and received monetary compensation for participation. The study was approved by the local ethics committee.

\section{Stimuli}

Stimuli were photos showing a male pianist's right hand playing sequences of chords on the piano (Yamaha Clavinova CLP150; Yamaha Music Europe GmbH, Rellingen, Germany). To maximally address action planning processes, we used photos rather than videos (cf. Sammler, Novembre, et al., 2013; Novembre \& Keller, 2011) obtaining more precise onset times of target chord presentation. In two sessions, we presented a total of 72 sequences that were all different from each other in terms of melodic contour. All sequences were composed according to the rules of classical harmony. The first chord always represented the tonic. The second chord could be tonic, mediant, or subdominant. Chords at the third position were subdominant, dominant, or dominant six-four chords, and chords at the fourth position were dominant seventh chords. At the last position, the target chord of each sequence was manipulated in terms of Syntax (syn) and Manner (man) in a $2 \times 2$ factorial design. Thirty-six sequences were conventional in terms of both Syntax and Manner (syn congruent/man correct), 12 were violated in terms of Syntax (syn incongruent/man correct), 12 in terms of Manner (syn congruent/man incorrect), and 12 in terms of both factors (syn incongruent/man incorrect). More precisely, syn congruent/man correct $\left(\mathrm{S}_{\mathrm{C}} \mathrm{M}_{\mathrm{c}}\right)$ sequences ended with a tonic (a chord typically used to resolve a musical sequence) played with conventional fingering; syn incongruent/man correct $\left(\mathrm{S}_{\mathrm{i}} \mathrm{M}_{\mathrm{c}}\right)$ sequences ended with a Neapolitan chord (a minor subdominant with a diminished sixth instead of a fifth, rarely used in classical harmony to resolve a musical sequence) played with conventional fingering; the syn congruent/man incorrect $\left(\mathrm{S}_{\mathrm{c}} \mathrm{M}_{\mathrm{i}}\right)$ sequences ended on a syntactically congruent tonic chord but played with an unconventional fingering; and finally the double violation (syn incongruent/man incorrect, $\mathrm{S}_{\mathrm{i}} \mathrm{M}_{\mathrm{i}}$ ) was constituted by a Neapolitan chord played with an unconventional fingering. The fingering adopted by the model hand was chosen by a piano teacher with 24 years of experience conforming to the fingering taught in classical piano lessons. This was aimed to achieve smoothness and movement economy between chord transitions (i.e., $124,125,135$, where 1 represents the thumb; 2 represents the index; and 3, 4, and 5 indicate the middle, the ring, and the little finger, respectively). Conversely, the manner manipulation of the target chord consisted of a fingering that was anatomically awkward and highly unlikely to be used (i.e., 123, 235, 245). The fingering of the last chord was rated by nine pianists on a scale from 1 (very conventional) to 9 (very unconventional). An ANOVA with the factors Syntax (congruent/incongruent) and Manner (correct/incorrect) on the mean ratings yielded a main effect of Manner $\left[F(1,8)=932.3, p<.001, \eta_{\mathrm{p}}^{2}=.991\right]$, but neither main effect of Syntax $[F(1,8)<1, p=.721$, $\left.\eta_{\mathrm{p}}^{2}=.017\right]$ nor interaction of the two factors $[F(1,8)=$ $\left..206, p=.662 ; \eta_{\mathrm{p}}^{2}=.025\right]$, confirming the motor unconventionality of the chosen fingering, and the independence of the syntax from the manner manipulation. All chords consisted of three keystrokes. Four tonalities with either two or four sharps or flats in the key signatures, that is, $\mathrm{D}, \mathrm{E}, \mathrm{B} b$, and $\mathrm{A} b$ major, were used with equal probability for each condition to balance the average amount of black and white keys in syntactically congruent and incongruent chords and to thus equate their visual surface structure and difficulty of execution. Red circles were superimposed on top of each pressed key for the whole duration of the photo to facilitate the recognition of the pressed keys. Sequences of two different lengths were created: fivechord sequences (long context) and two-chord sequences (short context). The two-chord sequences were identical to the last two chords of the five-chord sequences; thus, the long and short sequences differed only in the strength of the predictability of the last chord. In addition, comparing 
the four conditions across the two contexts allowed us to control for motor differences between conditions, that is, naturally longer hand trajectories from the penultimate to the syntactically incongruent $\left(\mathrm{S}_{\mathrm{i}} \mathrm{M}_{\mathrm{c}}\right.$; due to different keys) and the manner incorrect $\left(\mathrm{S}_{\mathrm{C}} \mathrm{M}_{\mathrm{i}}, \mathrm{S}_{\mathrm{i}} \mathrm{M}_{\mathrm{i}}\right.$; due to hand rotation) chords than to the not manipulated chords $\left(\mathrm{S}_{\mathrm{C}} \mathrm{M}_{\mathrm{C}}\right)$. Finally, it should be noted that the sequence-final tonic chords naturally share a number of keys with the harmonically related context. To control for the possibility that final tonics may be merely motorically primed by the repeated use of these keys, we also allowed the final correct manner to be partly motorically primed by presenting the respective fingering on average 1.1 times in the context. The balanced repetition of tonic key configuration (1.3 times) and final chord fingering, that is, the similar likelihood of motor priming, discloses any effect that occurs in the syntax but not manner conditions as related to syntactic (not motor) priming. Each sequence started with 2-sec presentation of a preparatory photo showing a stationary hand poised to press the three keys associated with the first chord. Then the following photos were presented at a rate of 2 sec per photo (total duration: 12-sec long sequences, 6-sec short sequences).

\section{Procedure}

Participants were seated in front of a MIDI (musical instrument digital interface) piano (Yamaha Clavinova CLP150) and watched the photo sequences on a computer monitor (100-Hz refresh rate). Simultaneously, they were required to execute the chords they saw, one by one, with their right hand on the piano, as quickly and accurately as possible, both in terms of the keys (syntax) and in terms of fingering (manner). Note that the piano was muted and no sound was presented with the photos, that is, the experiment

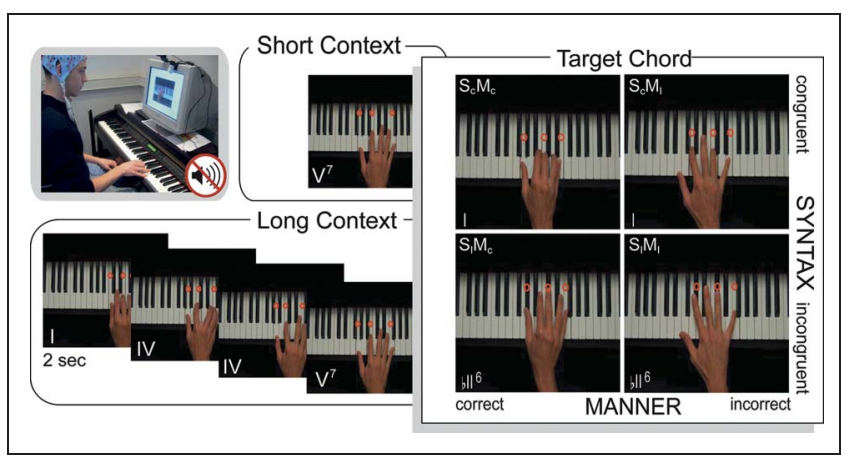

Figure 1. Experimental design. In the total absence of musical sound, pianists executed chord progressions with their right hand by copying (as fast and accurately as possible) the posture of a performing model hand shown in sequences of photos. The target chord of each progression was manipulated in terms of keys (congruent/ incongruent Syntax) and fingering (conventional/unconventional Manner) in a $2 \times 2$ factorial design and was presented at the end of a five- or two-chord sequence (long/short Context) to induce different strengths of predictability. took place in total absence of musical sounds. Each trial started with a visual fixation cross of 0.5 -sec duration and ended with a black screen for $1.5 \mathrm{sec}$ after the final photo of the stimulus sequence (Figure 1).

Participants were invited for two sessions in which they were presented with the same stimuli. Each session consisted of six experimental blocks, one for each of the three violation conditions $\left(\mathrm{S}_{\mathrm{i}} \mathrm{M}_{\mathrm{c}}, \mathrm{S}_{\mathrm{C}} \mathrm{M}_{\mathrm{i}}, \mathrm{S}_{\mathrm{i}} \mathrm{M}_{\mathrm{i}}\right)$ and separately for long and short sequences. Each block contained a total of 48 trials: 24 nonviolated trials $\left(\mathrm{S}_{\mathrm{C}} \mathrm{M}_{\mathrm{c}}\right)$ intermixed with 24 trials of the respective violation condition. Block order was counterbalanced across participants and alternated between blocks with long and short sequences. To acquaint participants with the unusual and challenging task and increase accuracy, in the first session, they all received a training of 24 trials (50\% nonviolated) for all the violation conditions in both long and short context. Different tonalities were used for the training ( $G, F, D b$, and $\mathrm{B}$ major) than in the main experiment.

At the end of the experiment, participants filled out a questionnaire to assess how much they relied on auditory imagery, motor imagery, and/or theoretical knowledge of western harmony to do the task. Their piano expertise was estimated as the sum of training hours per day across all years of piano lessons.

Stimulus presentation and response registration were controlled by Presentation software (Version 14.9, Neurobehavioral System, Inc., Berkeley, CA). Through a (custombuilt) MIDI interface, the MIDI piano key values were converted into a serial signal compatible with Presentation software. This allowed us to compute the RTs of the keystrokes in relation to the onset of the target chord photo. Moreover, a video camera placed above the keyboard recorded the pianist's hand from an aerial view, allowing us to detect (offline) trials in which the pianists used a different fingering from that shown in the photos.

\section{EEG Data Acquisition}

The EEG recordings were acquired from $61 \mathrm{Ag} / \mathrm{AgCl}$ electrodes (Fpz, Fp1, Fp2, AFz, AF3, AF4, AF7, AF8, Fz, F3, F4, F5, F6, F7, F8, F1, FC2, FCz, FC3, FC4, FC5, FC6, FT7, FT8, FC1, F2, Cz, C1, C2, C3, C4, C5, C6, T7, T8, CPz, CP3, CP4, CP5, CP6, TP7, TP8, P1, P2, Pz, P3, P4, P5, P6, P7, P8, CP1, CP2, POz, PO3, PO4, PO7, PO8, O1, O2, Oz) according to the international 10-20 system (Sharbrough et al., 1991). The left mastoid (M1) served as reference. Three additional electrodes were placed on the sternum as common ground, on the right mastoid bone (M2), and on the tip of the nose for offline re-referencing. The EOG was recorded by two bipolar montages, one with electrodes located above and below the left eye and the other with two electrodes placed on the outer canthus of each eye. Signals were amplified using a 24-bit Brainvision QuickAmp 72 amplifier (Brain Products $\mathrm{GmbH}$, Gilching, Germany) with input impedance below $5 \mathrm{k} \Omega$ and digitized at a 500-Hz sampling rate. 
Figure 2. (A) Mean RTs during imitation of syntactically incongruent (dashed line) and congruent chords (solid line; left) and during imitation of manner incorrect (dashed line) and correct chords (solid line; right) in the long and short context. (B) Number of key errors (left) and fingering errors (right) during imitation of syntactically incongruent and congruent chords in the long and short context. Error bars indicate 1 SEM. $* * * p<.001, * * p<.01$ $* p<.05$.

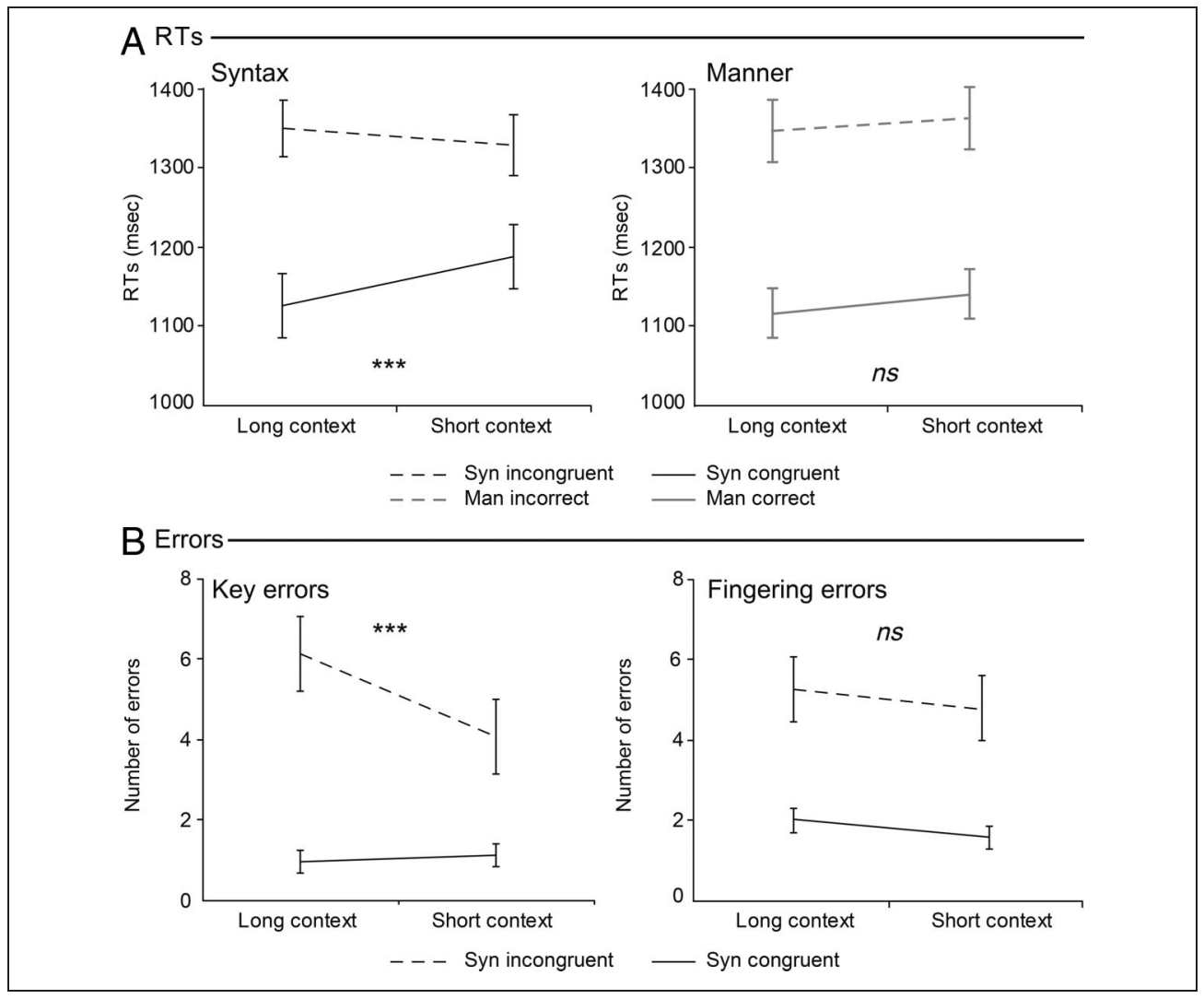

\section{Behavioral Data Analysis}

RTs and execution errors of the last chord of each trial were analyzed in accordance with Novembre and Keller (2011). The minimum requirement for including a participant's data into the analysis was correct responses on $50 \%$ of trials. Trials were considered valid when three conditions were satisfied: (1) both the last and the second last chord had to be correctly imitated in terms of keys and fingering (for the error analysis we included the trials correctly imitated in the second last but incorrectly in the last chord), (2) the keystrokes within a chord had to be synchronous (i.e., no more than $150 \mathrm{msec}$ should intervene between the first and the last of the three keystrokes), and (3) mean RTs of the three keystrokes after the onset of the target chord photo had to stay within 3000 msec (cf. Drost, Rieger, Brass, Gunter, \& Prinz, 2005). RTs were calculated by subtracting the time of execution of the target chord (i.e., mean of the times of three keystrokes composing the chord) from the onset time of the last photo showing the target chord. The fingering performed by each pianist was analyzed through offline inspection of the video recordings in which the fingers employed by the participants were compared with the fingers presented in the stimulus photos. Statistical evaluation of the RT data was done using three-way repeated-measures ANOVA with the factors Syntax (congruent/incongruent), Manner (correct/ incorrect), and Context (long/short). Errors were analyzed with an analogous ANOVA, but with the additional withinsubject factor Error type (key/fingering error).

\section{EEG Data Analysis}

Data analysis was carried out using EEGLAB toolbox 9.01 (Delorme \& Makeig, 2004) implemented in MATLAB 7.7. The EEG data were offline re-referenced to the algebraic mean of the mastoids and were $0.3-\mathrm{Hz}$ high-pass filtered (fir, 5854 points, Blackman window). Strong muscle artifacts, electrode drifts, or technical artifacts were manually rejected. Independent component analysis was used for linear decomposition of the continuous data to remove the contributions of artifact sources (slow drifts, eye blink/movement, and muscle artifacts) on the scalp sensors. After $25-\mathrm{Hz}$ low-pass filtering (fir, 110 points, Blackman window), epochs of -200 to $1500 \mathrm{msec}$, time-locked to the onset of the photo of the last chord, were extracted from the data. Epochs were rejected whenever signal voltages exceeded $\pm 80 \mu \mathrm{V}$ in one or more electrodes. Nonrejected trials were averaged separately for each condition and baseline-corrected $(-200 \mathrm{msec}$ before the onset of the target photo). Only correct trials according to the behavioral analysis were included in the ERP statistical analysis (i.e., mean number of trials $\pm S D$ for $\mathrm{S}_{\mathrm{c}} \mathrm{M}_{\mathrm{c}}, \mathrm{S}_{\mathrm{i}} \mathrm{M}_{\mathrm{c}}, \mathrm{S}_{\mathrm{c}} \mathrm{M}_{\mathrm{i}}, \mathrm{S}_{\mathrm{i}} \mathrm{M}_{\mathrm{i}}$ in the long context: $122.9 \pm 10$, $38.1 \pm 5.4,37.7 \pm 4.8,35.8 \pm 5.5$; in the short context: $131.3 \pm 6,41.3 \pm 4.4,40.4 \pm 4.7,38.3 \pm 6.2$ ). 
Effects of Syntax, Manner, and Context were analyzed time-locked to the onset of the last (target) photo of the sequence. Mean amplitudes were computed separately for each condition over nine ROIs and for three specific time windows. The ROIs comprised (i) left anterior (F3, F5, F7, FC3, FC5, FT7, AF3), (ii) left central (C3, C5, T7, CP3, CP5, TP7), (iii) left posterior (P3, P5, P7, PO3, PO7), (iv) middle anterior (F1, FZ, F2, FC1, FCZ, FC2, AFZ), (v) middle central (C1, CZ, C2, CP1, CPZ, CP2), (vi) middle posterior (P1, PZ, P2, POZ), (vii) right anterior (F4, F6, F8, FC4, FC6, FT8, AF4), (viii) right central (C4, C6, T8, CP4, CP6, TP8), (ix) right posterior (P4, P6, P8, PO4, PO8). Three time windows (i) from 210 to $520 \mathrm{msec}$, (ii) from 520 to $800 \mathrm{msec}$, and (iii) from 800 to $1200 \mathrm{msec}$ were selected by visual inspection of the ERPs and topography plots shown in Figures 2 and 3. As objective and external criteria independent from the data, borders of the time windows were set to time points at which either a change in polarity or in topography was found, assuming that different map topographies and polarities directly indicate different underlying generators, that is, different cognitive processes (Michel et al., 2004). The same time windows were used in the analysis of the two conditions. Statistical analysis of mean amplitude values was carried out by means of five-way ANOVAs with the repeated-measures factors Syntax (congruent/incongruent) $\times$ Manner $($ correct/incorrect $) \times$ Context (long/short) $\times$ Laterality (left/middle/right) $\times$ AntPost (anterior/central/posterior), separately for each time window.

\section{RESULTS}

\section{Behavioral Data}

RTs

Statistical values of the $2 \times 2 \times 2$ repeated-measures ANOVA with the factors Syntax (congruent/incongruent), Manner (correct/incorrect), and Context (long/short) are reported in Table 1 . These results revealed main effects of Syntax and Manner, indicating that imitation of the syntactically incongruent as well as manner violated chords was generally slower compared to chords that contained no such violations. No main effect of Context was found, showing that RTs for the imitation of target chords was comparable between long and short sequences. Notably, a highly significant Syntax $\times$ Context interaction showed that more in the long than in the short context the execution of syntactically congruent chords was faster compared to incongruent chords. Conversely, no interaction between Manner $\times$ Context was found (Figure $2 \mathrm{~A}$ ). This finding suggests that the harmonic structure of the musical context rather than the motor pattern familiarity drove the motoric prediction of the target chord and that the

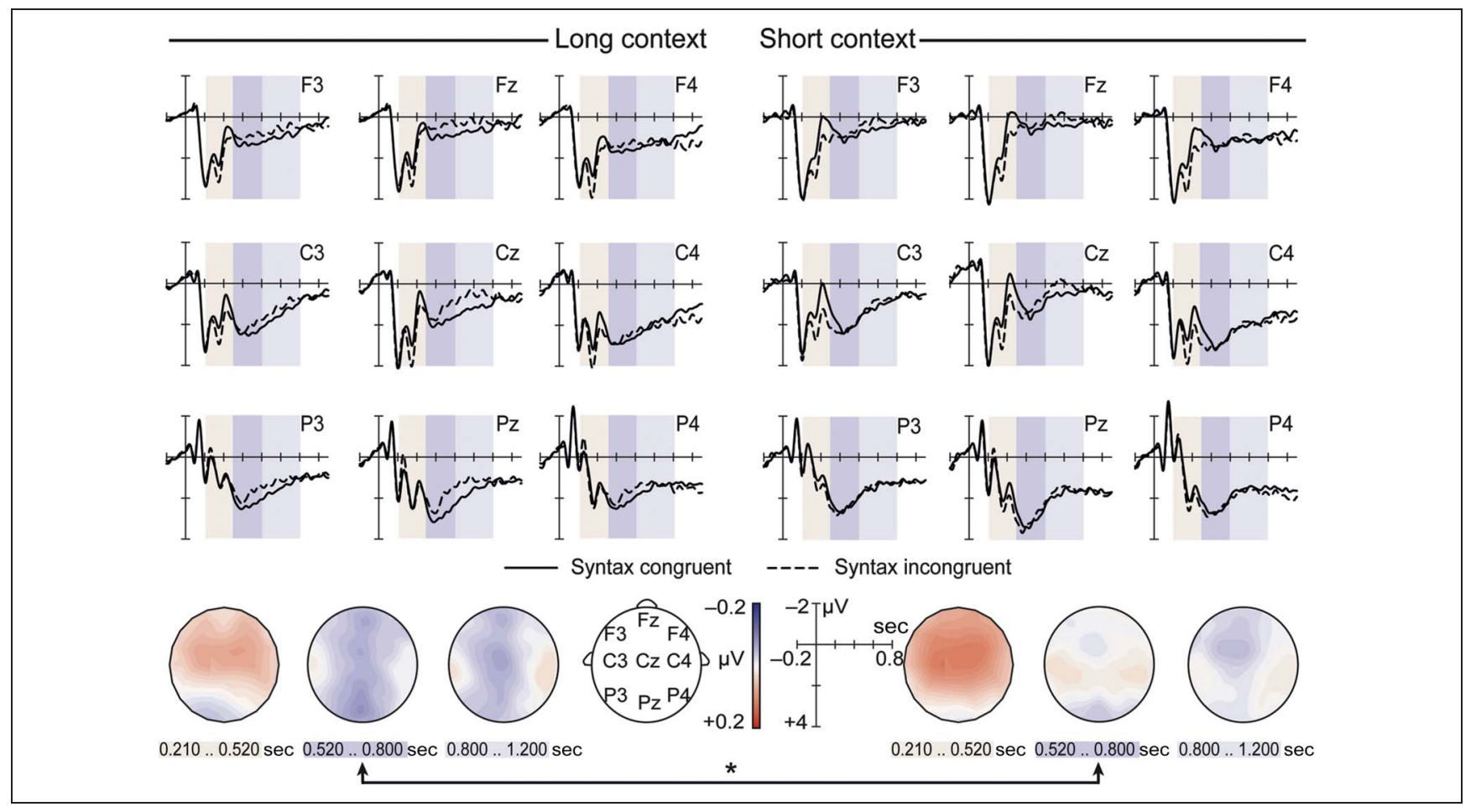

Figure 3. Effect of Syntax. ERPs evoked by syntactically incongruent (dotted line) compared to congruent (solid line) chords in the long (left) and short (right) context across all trials. The three time windows are shaded according to their polarity (red for positivity, blue for negativity). Topography maps for each statistical time window (lower row) depict the difference potentials of syntactically incongruent minus congruent chords (arrows below indicate the interaction between Syntax and Context). ${ }^{*} * p<.001, * * p<.01,{ }^{*} p<.05$. 
Table 1. Results of the ANOVA on RTs with the Factors Syntax $\times$ Manner $\times$ Context

\begin{tabular}{lcrcc}
\hline Effect & $d f$ & \multicolumn{1}{c}{$F$} & $p$ & $\eta_{p}^{2}$ \\
\hline $\mathrm{S}$ & 1,25 & $\mathbf{8 0 . 1 6}$ & $\mathbf{. 0 0 0}$ & $\mathbf{. 7 6 2}$ \\
$\mathrm{M}$ & 1,25 & $\mathbf{1 3 3 . 6 5}$ & $\mathbf{. 0 0 0}$ & $\mathbf{. 8 4 2}$ \\
$\mathrm{C}$ & 1,25 & 1.522 & .229 & .057 \\
$\mathrm{~S} \times \mathrm{C}$ & 1,25 & $\mathbf{5 2 . 5 6}$ & $\mathbf{. 0 0 0}$ & $\mathbf{. 6 7 8}$ \\
$\mathrm{M} \times \mathrm{C}$ & 1,25 & .604 & .445 & .024 \\
$\mathrm{~S} \times \mathrm{M} \times \mathrm{C}$ & 1,25 & $\mathbf{4 . 7 8}$ & $\mathbf{. 0 3 8}$ & $\mathbf{. 1 6 0}$ \\
\hline
\end{tabular}

Bold values indicate significant results $(p<.05)$. Partial eta squared: $\eta_{\mathrm{p}}^{2}>.5$, large effect size; $\eta_{\mathrm{p}}^{2}>.3$, medium effect size; $\eta_{\mathrm{p}}^{2} \leq .1$, small effect size (Bortz \& Döring, 2003). S = Syntax; M = Manner; C = Context.

prediction concerned the musical goal (Syntax) rather than the movement selection (Manner).

A three-way interaction of Syntax $\times$ Manner $\times$ Context suggested a reciprocal influence of syntax and manner processing in relation to the Context. We calculated separate ANOVAs for the manner correct and incorrect trials with the factors Syntax and Context and for the syntax congruent and incongruent trials with the factors Manner and Context. This analysis yielded a Syntax $\times$ Context interaction in both manner correct $[F(1,25)=71.99, p<$ $\left..001, \eta_{\mathrm{p}}^{2}=.742\right]$ and, although weaker, in the manner incorrect trials $\left[F(1,25)=5.98, p=.022, \eta_{\mathrm{p}}^{2}=.193\right]$, whereas a Manner $\times$ Context interaction was found only in the syntax congruent trials $[F(1,25)=4.505, p=.044$, $\left.\eta_{\mathrm{p}}^{2}=.153\right]$ and not in the syntax incongruent trials $[F(1,25)=$ $\left.1.649, p=.211, \eta_{\mathrm{p}}^{2}=.062\right]$. This indicates that while the syntactic prediction effect (Syntax $\times$ Context interaction), although weaker, held in presence of the concurrent manner violation, the manner was facilitated (Manner $\times$ Context) only when the pianists' syntactic prediction was fulfilled (syntax congruent trials). These data suggest that the syntax of the context primes primarily the motor program of the musical goal, which in turn may trigger information about optimal movement parameters for its execution. In other words, movement selection is facilitated only when the higher plan on the musical goal is confirmed.

\section{Error Analysis}

Errors in terms of pressed keys and fingering were counted separately. Trials with both error types were excluded from the analysis (as in Novembre \& Keller, 2011). Key and fingering errors are assumed to reflect distinct cognitive processes associated with the musical goal (Syntax) and the specific movement used in the execution (Manner), respectively.

A $2 \times 2 \times 2 \times 2$ repeated-measures ANOVA with the factors Syntax, Manner, Context, and Error type (key/ fingering errors; for statistical values, see Table 2) revealed that-overall-less errors were committed during execution of syntactically congruent compared to incongruent chords (main effect of Syntax) as well as during the imitation of manner correct compared to incorrect chords (main effect of Manner). Also, less errors were committed in the short compared to the long context (main effect of Context), whereas there was no significant difference between number of key and fingering mistakes (no significant main effect of Error type). The interactions of Syntax $\times$ Error type and Manner $\times$ Error type revealed that Syntax and Manner conditions were associated with greater amount of key and fingering errors, respectively. Importantly, a Syntax $\times$ Context $\times$ Error type interaction indicated that key errors, but not fingering errors, were more prevalent in the long than in the short context during the execution of syntactically incongruent chords, irrespective of the manner. Indeed, follow-up ANOVAs with the factors Syntax and Context, calculated separately for the key and the fingering errors (Figure 2B), yielded a significant Syntax $\times$ Context interaction for the key errors $\left[F(1,25)=7.164, p=.013, \eta_{\mathrm{p}}^{2}=.223\right]$, but not for the fingering errors $\left[F(1,25)=2.599, p=.122, \eta_{\mathrm{p}}^{2}=.093\right]$. These data indicate that the harmonic structure of the context strongly affected the motor program of the musical goal, irrespective of the specific movement selection. Additionally, similar to what was observed in the RTs, we found that during the execution of the manner incorrect chords more fingering errors were committed in the long than in the short context but only when the syntax was congruent [Manner $\times$ Context interaction on the fingering errors across syntactically congruent trials: $F(1,25)=$ $9.120, p=.006, \eta_{\mathrm{p}}^{2}=.267$; across syntactically incongruent trials: $\left.F(1,25)=1.161, p=.292, \eta_{\mathrm{p}}^{2}=.044\right]$. This finding confirms that the selection of which fingers to use was facilitated in the long context only when the musical goal matched the (syntactic) predictions.

Table 2. Results of the ANOVA on Number of Errors with the Factors Syntax $\times$ Manner $\times$ Context $\times$ Error Type

\begin{tabular}{lcccc}
\hline Effect & $d f$ & $F$ & $p$ & $\eta_{p}^{2}$ \\
\hline $\mathrm{S}$ & 1,25 & $\mathbf{3 9 . 8 9 6}$ & $\mathbf{. 0 0 0}$ & $\mathbf{. 6 1 5}$ \\
$\mathrm{M}$ & 1,25 & $\mathbf{2 0 . 9 0 7}$ & $\mathbf{. 0 0 0}$ & $\mathbf{. 4 5 5}$ \\
$\mathrm{C}$ & 1,25 & $\mathbf{5 . 7 7 9}$ & $\mathbf{. 0 2 4}$ & $\mathbf{. 1 8 8}$ \\
$\mathrm{Et}$ & 1,25 & 3.276 & .082 & .116 \\
$\mathrm{~S} \times \mathrm{Et}$ & 1,25 & $\mathbf{9 . 0 2 8}$ & $\mathbf{. 0 0 6}$ & $\mathbf{. 2 6 5}$ \\
$\mathrm{M} \times \mathrm{Et}$ & 1,25 & $\mathbf{3 2 . 1 4 6}$ & $\mathbf{. 0 0 0}$ & $\mathbf{. 5 6 3}$ \\
$\mathrm{S} \times \mathrm{C} \times \mathrm{Et}$ & 1,25 & $\mathbf{8 . 8 6 8}$ & $\mathbf{. 0 0 6}$ & $\mathbf{. 2 6 2}$ \\
\hline
\end{tabular}

Bold values indicate significant results $(p<.05)$. Partial eta squared: $\eta_{\mathrm{p}}^{2}>.5$, large effect size; $\eta_{\mathrm{p}}^{2}>.3$, medium effect size; $\eta_{\mathrm{p}}^{2} \leq .1$, small effect size (Bortz \& Döring, 2003). $\mathrm{S}=$ Syntax; $\mathrm{M}=$ Manner; $\mathrm{C}=$ Context; $\mathrm{Et}=$ Error type. 
Table 3. Results of the ANOVAs with the Factors Syntax $\times$ Manner $\times$ Context $\times$ Laterality $\times$ AntPost for Each Time Window

\begin{tabular}{|c|c|c|c|c|c|c|c|c|c|c|}
\hline \multirow[b]{2}{*}{ Effect } & \multirow[b]{2}{*}{$d f$} & \multicolumn{3}{|c|}{$1 s t \mathrm{tw}: 210 \ldots 520 \mathrm{msec}$} & \multicolumn{3}{|c|}{ 2nd tw: $520 \ldots 800 \mathrm{msec}$} & \multicolumn{3}{|c|}{$3 r d$ tw: $800 \ldots 1200 \mathrm{msec}$} \\
\hline & & $F$ & $p$ & $\eta_{p}^{2}$ & $F$ & $p$ & $\eta_{p}^{2}$ & $F$ & $p$ & $\eta_{p}^{2}$ \\
\hline \multicolumn{11}{|l|}{ Effect of Syntax } \\
\hline S & 1,25 & 5.733 & .024 & .187 & 1.019 & .322 & .039 & $<1$ & .352 & .035 \\
\hline $\mathrm{S} \times \mathrm{C}$ & 1,25 & 1.578 & .221 & .059 & 1.673 & .208 & .063 & $<1$ & .650 & .008 \\
\hline$S \times L$ & 2,50 & $<1$ & .417 & .033 & 3.965 & .029 & .137 & 10.894 & .000 & .304 \\
\hline $\mathrm{S} \times \mathrm{L} \times \mathrm{C}$ & 2,50 & 1.481 & .238 & .056 & 1.082 & .159 & .073 & $<1$ & .475 & .029 \\
\hline $\mathrm{S} \times \mathrm{A}$ & 2,50 & 8.225 & .007 & .248 & 1.543 & .227 & .058 & 1.017 & .369 & .039 \\
\hline $\mathrm{S} \times \mathrm{A} \times \mathrm{C}$ & 2,50 & $<1$ & .912 & .001 & $<1$ & .835 & .003 & $<1$ & .557 & .023 \\
\hline $\mathrm{S} \times \mathrm{A} \times \mathrm{L}$ & 4,100 & 2.015 & .120 & .075 & $<1$ & .660 & .021 & 2.977 & .051 & .103 \\
\hline $\mathrm{S} \times \mathrm{A} \times \mathrm{L} \times \mathrm{C}$ & 4,100 & 1.083 & .360 & .042 & 2.886 & .035 & .103 & 1.685 & .179 & .063 \\
\hline
\end{tabular}

Effect of Manner

$\begin{array}{lcccccccccc}\mathrm{M} & 1,25 & 1.630 & .213 & .061 & \mathbf{2 9 . 0 1 4} & \mathbf{. 0 0 0} & \mathbf{. 5 3 7} & <1 & .402 & .028 \\ \mathrm{M} \times \mathrm{C} & 1,25 & <1 & .487 & .008 & 1.715 & .202 & .064 & 4.002 & .056 & .138 \\ \mathrm{M} \times \mathrm{L} & 2,50 & \mathbf{2 4 . 2 0 2} & \mathbf{. 0 0 0} & \mathbf{. 4 9 2} & \mathbf{1 1 . 4 8 6} & \mathbf{. 0 0 0} & \mathbf{. 3 1 5} & \mathbf{9 . 4 0 1} & \mathbf{. 0 0 1} & \mathbf{. 2 7 3} \\ \mathrm{M} \times \mathrm{L} \times \mathrm{C} & 2,50 & 1.064 & .347 & .041 & <1 & .520 & .025 & 1.401 & .256 & .053 \\ \mathrm{M} \times \mathrm{A} & 2,50 & \mathbf{9 . 5 9 2} & \mathbf{. 0 0 3} & \mathbf{. 2 7 7} & 2.004 & .168 & .074 & <1 & .425 & .028 \\ \mathrm{M} \times \mathrm{A} \times \mathrm{C} & 2,50 & \mathbf{1 0 . 2 7 9} & \mathbf{. 0 0 3} & \mathbf{. 2 9 1} & \mathbf{7 . 8 3 3} & \mathbf{. 0 0 5} & . \mathbf{2 3 9} & 1.230 & .283 & .047 \\ \mathrm{M} \times \mathrm{A} \times \mathrm{L} & 4,100 & \mathbf{9 . 3 8 7} & \mathbf{. 0 0 0} & \mathbf{. 2 7 3} & \mathbf{8 . 5 9 5} & \mathbf{. 0 0 0} & . \mathbf{2 5 6} & \mathbf{3 . 6 0 1} & \mathbf{. 0 2 4} & \mathbf{. 1 2 6} \\ \mathrm{M} \times \mathrm{A} \times \mathrm{L} \times \mathrm{C} & 4,100 & 1.165 & .328 & .045 & 1.552 & .205 & .058 & 1.558 & .210 & .059\end{array}$

Syntax and Manner Interaction

\begin{tabular}{lcccccccccc}
$\mathrm{S} \times \mathrm{M}$ & 1,25 & 1.164 & .291 & .044 & $<1$ & .869 & .001 & $<1$ & .964 & .000 \\
$\mathrm{~S} \times \mathrm{M} \times \mathrm{C}$ & 1,25 & $<1$ & .584 & .012 & 1.586 & .219 & .060 & 3.780 & .063 & .131 \\
$\mathrm{~S} \times \mathrm{M} \times \mathrm{C} \times \mathrm{L}$ & 2,50 & $<1$ & .926 & .002 & $<1$ & .419 & .033 & 3.039 & .068 & .108 \\
$\mathrm{~S} \times \mathrm{M} \times \mathrm{A}$ & 2,50 & 1.962 & .172 & .073 & $\mathbf{6 . 6 1 4}$ & .012 & .209 & $<1$ & .358 & .035 \\
$\mathrm{~S} \times \mathrm{M} \times \mathrm{C} \times \mathrm{A}$ & 2,50 & $<1$ & .714 & .006 & $<1$ & .594 & .012 & 1.128 & .304 & .043 \\
$\mathrm{~S} \times \mathrm{M} \times \mathrm{L} \times \mathrm{A}$ & 4,100 & $<1$ & .672 & .021 & 1.124 & .347 & .043 & $\mathbf{2 . 7 7 8}$ & .039 &. $\mathbf{1 0 0}$ \\
$\mathrm{S} \times \mathrm{M} \times \mathrm{L} \times \mathrm{A} \times \mathrm{C}$ & 4,100 & 1.137 & .340 & .044 & 1.633 & .187 & .061 & 1.249 & .297 & .048 \\
\hline
\end{tabular}

Bold values indicate the effects due to the difference in strength of potentials. Partial eta squared: $\eta_{\mathrm{p}}^{2}>.5$, large effect size; $\eta_{\mathrm{p}}^{2}>.3$, medium effect size; $\eta_{\mathrm{p}}^{2} \leq .1$, small effect size (Bortz \& Döring, 2003). $\mathrm{S}=$ Syntax; $\mathrm{M}=$ Manner; $\mathrm{C}=$ Context; $\mathrm{L}=$ Laterality; A = AntPost.

\section{EEG Data}

We were interested in distinguishing neurophysiological correlates of (i) the higher level of syntax-based motor programming (prediction of the musical goal, reflected by a Syntax $\times$ Context interaction) and (ii) the lower level of specific movement selection (prediction of a conventional optimal movement, reflected by a Manner $\times$ Context interaction). To this end, we analyzed (Table 3) the effects of (i) Syntax (Figure 3), (ii) Manner (Figure 4), and (iii) their interaction separately in three time windows (see EEG Data Analysis). Nonparametric clusterbased permutation tests with standard parameters in Fieldtrip (www.fieldtriptoolbox.org) revealed qualitatively similar results to those described below.

The analysis of the effects of Syntax and Manner revealed different neural signatures between 520 and $800 \mathrm{msec}$, in line with our hypothesis that the planning of a musical goal (Syntax) and the specific movements (Manner) rely on different mechanisms. 


\section{Effect of Syntax}

In the first time window (210-520 msec), syntactically incongruent compared to congruent chords elicited a positivity with a central scalp distribution as revealed by a significant main effect of Syntax and an interaction of Syntax $\times$ AntPost. This early effect did not differ between long and short context (i.e., no interaction of Syntax $\times$ Context), suggesting that it was not related to prediction. Most relevant, in the second time window (520-800 msec), syntactically incongruent compared to congruent chords evoked a centroparietal negativity that was present in the long and not in the short context. The four-way ANOVA showed a significant interaction of Syntax $\times$ Context $\times$ AntPost $\times$ Laterality demonstrating that the negativity was particularly strong in the long context and more enhanced in the midline central regions. In the third time window (800-1200 msec), the four-way ANOVA yielded an interaction of Syntax $\times$ Laterality, as well as a marginally significant interaction of Syntax $\times$ AntPost $\times$ Laterality, indicating a predominantly middle-central negativity that did not differ in amplitude between long and short context.

To evaluate whether the negativity between 520 and $800 \mathrm{msec}$ in the long context was influenced by auditory imagery, the difference wave in the middle central ROI $($ mean $=-0.516 \pm 1.384 \mu \mathrm{V})$ was correlated with the subjective ratings of the extent to which participants actively imagined the sound of the up-coming chord during performance. No significant correlation was found $[r(25)=$ $\left..261, p=.301, R^{2}=.046\right]$.

\section{Effect of Manner}

In the first time window (210-520 msec), a significant interaction of Manner $\times$ AntPost $\times$ Laterality revealed a left middle anterior positivity elicited by the manner incorrect compared with manner correct chords across all trials. This positivity was stronger in the long compared to the short context, as shown by a significant interaction of Manner $\times$ Context $\times$ AntPost. Follow-up ANOVAs with the factors Manner $\times$ Context calculated for each ROI confirmed a left middle anterior distribution of this effect [Manner $\times$ Context interaction, middle anterior: $F(1,25)=$ 7.920, $p=.009$; left anterior: $F(1,25)=1.188, p=.027$; right anterior: $F(1,25)=3.793, p=.063$; all $p s>.116$ in the other ROIs]. In the second time window (520$800 \mathrm{msec}$ ), a main effect of Manner indicated that manner incorrect chords elicited more positive potentials than manner correct chords with a predominately middle to left centroparietal distribution, as confirmed by a Manner $x$ AntPost $\times$ Laterality interaction. A Manner $\times$ Context $\times$ AntPost interaction showed that the positivity in the short context did not extend as far anteriorly as in the long context. This difference in scalp distribution was confirmed by significant Manner $\times$ Context interactions in the anterior regions as revealed by follow-up ANOVAs with the factors

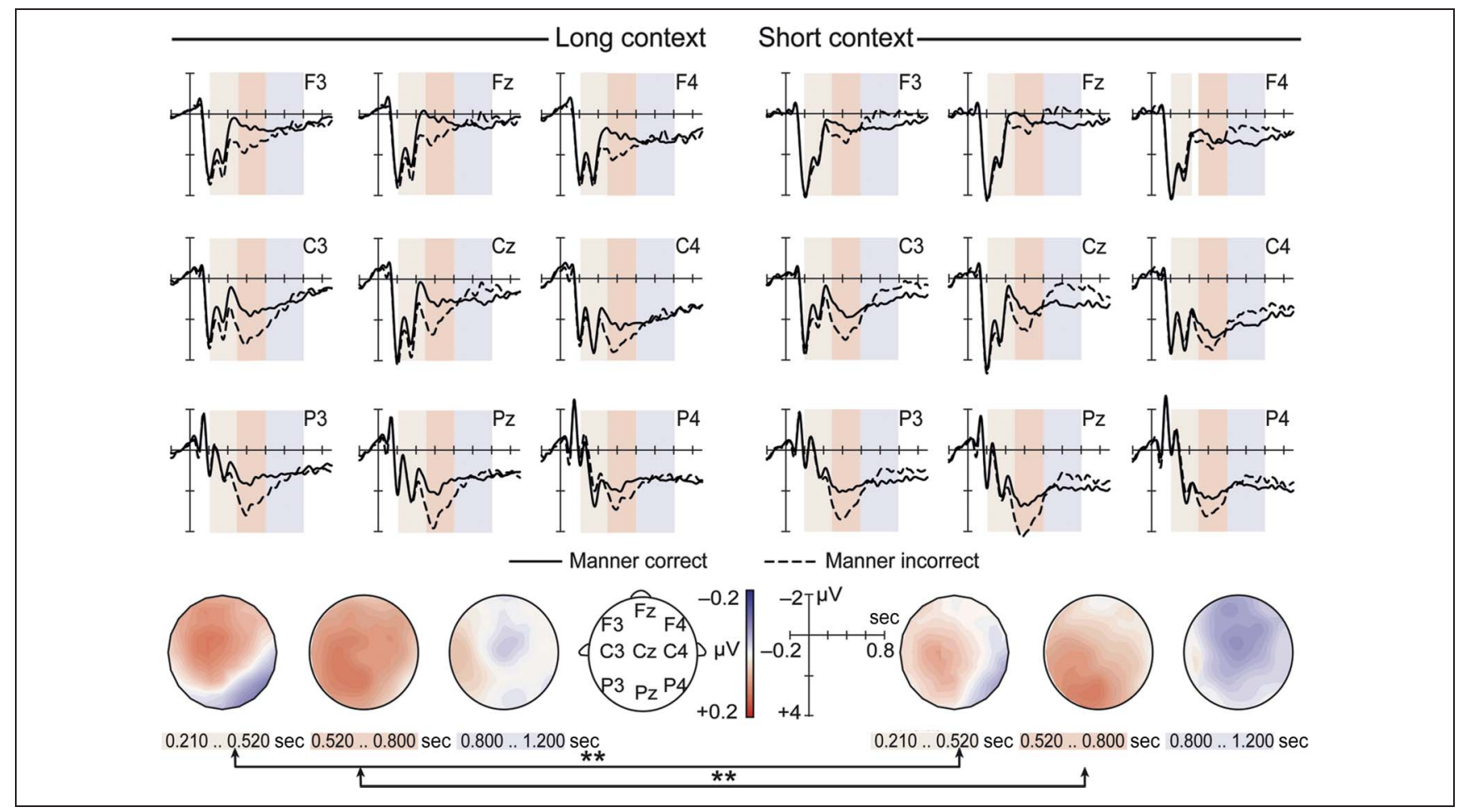

Figure 4. Effect of Manner. ERPs evoked by target chords played with incorrect (dotted line) compared to correct (solid line) manner in the long (left) and short (right) context across all trials. Time windows of the three time windows are shaded according to their polarity (red for positivity, blue for negativity). Topography maps for each statistical time window (lower row) depict the difference potentials of manner incorrect minus correct chords (arrows below indicate the interaction between Manner and Context). ${ }^{* * *} p<.001, * * p<.01, * p<.05$. 
Manner $\times$ Context calculated for each ROI [middle anterior: $F(1,25)=7.813, p=.010$; right anterior: $F(1,25)=$ $10.884, p=.003$; left anterior: $F(1,25)=3.844, p=.061$; all $p \mathrm{~s}>.161$ in the other ROIs]. In the third time window (800-1200 msec), an interaction of Manner $\times$ AntPost $\times$ Laterality indicated a middle centrally distributed negativity elicited by the manner incorrect compared to the manner correct chords that tended to be larger in the short compared to the long context [Manner $\times$ Context: $F(1,25)=$ 4.002, $p=.056]$.

\section{Interaction Effects}

Finally, we analyzed how far the effects of Syntax and Manner described above reciprocally interact. To this end, we tested for interactions that involved the factors Syntax $\times$ Manner $\times$ Context (and any topographical factor). No such interactions were found in any of the three time windows (see Table 3). Consequently, no further split of the general linear model was performed.

\section{DISCUSSION}

Action plans are hierarchically organized, with higher levels representing the general goal of an action and lower levels concerning the specific movements required to realize the goal (Uithol et al., 2012). This study aimed to differentiate action planning based on higher-order syntactic structures (Syntax) from lower nonsyntactic processes of movement selection (Manner) in expert pianists. Therefore, behavioral and neural indices of motor prediction were examined during the execution of chords that contained either a syntax or a manner violation and that were primed by long or short musical contexts.

We found (i) a strong context-dependent priming effect on the execution of syntactic violations (RTs and errors), indicating that plans of musical goals are made ahead according to the musical context. Crucially, (ii) no contextual priming was observed during the execution of manner violations, unless the syntax was congruent. In line with models of action hierarchy (Grafton \& Hamilton, 2007), this suggests a priority of planning the goal of the musical action (Syntax) that in turn can prime the selection of the optimal movement parameters (Manner). Finally, (iii) different electrophysiological signals were elicited by the syntactically incongruent chords (centroparietal negativity) and manner incorrect chords (posterior positivity). These signatures may represent the different levels of action planning, pertaining to higher levels of syntax-based motor plans versus lower levels of movement parameter setting, respectively.

\section{Behavior}

In line with previous findings (Sammler, Novembre, et al., 2013; Novembre \& Keller, 2011), syntactically incongruent chords were executed more slowly and evoked more key mistakes than congruent chords, particularly when primed by a long musical context. Conversely, execution times and number of fingering mistakes were commensurately higher in manner incorrect than correct chords, irrespective of context length. This pattern of results not only excludes an interpretation in terms of mere motor priming (which should have led to similar context effects in syntax and manner; see Methods) but indicates that particularly the syntactic structure of the musical context narrows down the probabilities of chord transitions, thus leading the pianists to (motorically) anticipate the execution of the most likely harmonically coherent chord (Syntax). By contrast, the specific movement parameters seem to be far less strongly determined by the preceding context, despite high familiarity with the types of chord progressions employed in the paradigm. Notably, the context dependency of syntactically incongruent chords was observed irrespective of whether the concurrent manner was correct or incorrect, although it was stronger in the former due to movement familiarity. This shows that, in experts, distal goals are the main drivers of motor predictions regardless of how the goal is realized. At the same time, our data further suggest that the preplanned goal tends to prime the selection of optimal movement parameters required to achieve the goal. We ground this assumption on the observation that manner incorrect chords showed context sensitivity both in terms of execution time and number of fingering errors, but exclusively in syntactically congruent trials (i.e., when the preplanned goal was valid). This suggests that the specific movement selection constitutes a late stage of motor preparation dependent on the action plan concerning the more distal musical goal.

In conclusion, motor predictions concerning the musical goal, prior to the manner, are consistent with the framework of "generalized motor programs" (for a review, see Summers \& Anson, 2009), as knowledge structures allow a given class of movements to be executed in different ways, depending on underlying parameter settings. Furthermore, it is reminiscent of imitation studies showing a hierarchical organization of action in which the action goal is prioritized over the short-term selected movements (Wohlschläger et al., 2003; Bekkering et al., 2000).

\section{ERPs}

The execution of the syntax and manner violations elicited different electrophysiological patterns between 520 and 800 msec: We found that the syntax violations evoked a centroparietal negativity in the long and not in the short context (similar to Sammler, Novembre, et al., 2013) whereas the execution of the manner violations elicited a positivity with left posterior scalp distribution. In line with integrated models of hierarchical organized motor plans (Grafton \& Hamilton, 2007), we claim that this distinction speaks in favor of a motor program level coding for the goal 
structure of an action (Syntax) and a lower motor level for computing the coordinated movement to a goal (Manner).

More specifically, the centroparietal negativity elicited by the syntax violation was modulated by the length of the musical context and thus matched the contextdependent effects in RTs and errors. This suggests a response-related nature of the negativity, which may be interpreted as a signal of high-level movement reprogramming following the cancellation of the prepotent response in face of the incongruity to be executed (Sammler, Novembre, et al., 2013; Leuthold \& Jentzsch, 2002). Importantly, this interpretation implies that the motor program for a structurally coherent musical goal was present at the moment of the target chord presentation, as it had been preplanned based on the syntactic context. Obviously, longer contexts lead to stronger syntax-based predictions of the musical goals that in turn require more effort in their revision (larger amplitude of the negativity, longer RTs, and a higher number of key errors in the long than in the short context). In a later time window (800-1200 msec), a late centrally distributed negativity, which resembles the contingent negative variation (Walter, Cooper, Aldridge, MacCallum, \& Winter, 1964), was elicited in all conditions similarly in the two contexts. This time window immediately preceded and partly overlapped with the execution of the final chord and might reflect the computation of muscle-specific commands common to all conditions (Cunnington, Windischberger, Deecke, \& Moser, 2003; Rektor, 2000). Indeed, the contingent negative variation is typically elicited before motor responses and specifically in the final stage of response preparation of externally cued movements (Smith, Johnstone, \& Barry, 2006).

Crucially, manner violations did not evoke a centroparietal negativity between 520 and $800 \mathrm{msec}$, as opposed to syntax violations. This discloses the negativity (in line with the behavioral results) as related to syntactic processes not motor priming (see Methods). Furthermore, if one accepts the idea that this negativity reflects the reprogramming of a preplanned motor response, its absence in the manner violations implies that the specific movement for execution had not been programmed at the time of the target chord presentation. This interpretation would be in line with the assumption that the musical goal is planned before movement selection.

Instead, the manner violations elicited a left posterior positivity in the time window between 520 and $800 \mathrm{msec}$ in both contexts, speaking in favor of a different nature of the syntax- and manner-related cognitive processes. This effect was preceded by an earlier positivity (210$520 \mathrm{msec}$ ) with anterior scalp distribution. Together, these potentials resemble the P300 complex composed of P3a and P3b, typically elicited by infrequent behaviorally relevant stimuli (Gómez, Flores, Digiacomo, Ledesma, \& González-Rosa, 2008) and modulated in amplitude by the probability of the deviant target (Duncan-Johnson \& Donchin, 1977, 1982). Interestingly, both the early and late positivities were stronger in the long than in the short context, revealing a context-dependent effect that obviously mismatches with the behavioral data. One explanation might be that, unlike the response-related ERPs in the syntax condition, these positivities rather reflect stimulusrelated processes that are contingent on the different sequential probabilities of the manner violation in long and short stimulus sequences. More precisely, given that the manner violation can be recognized as odd even in single photos (see Methods), its occurrence probability amounts to $10 \%$ in task blocks with long sequences and $25 \%$ in task blocks with short sequences. It should be noted that the same reasoning does not apply to the syntax violations that were only recognizable as part of the sequence. This amounts to an equal occurrence probability of $50 \%$ in both long and short sequences and should not lead to amplitude differences. In line with this, the detection of the syntax violations indeed evoked an early positivity (a P3a) that did not differ between long/ short contexts (for similar results, see also Sammler, Novembre, et al., 2013). Altogether, the perceptual detection of both syntax- and manner-related violations elicited a P3a; however, rather than a motor reprogramming phase as observed in the syntax violation (centroparietal negativity between 520 and $800 \mathrm{msec}$ ), the salient fingering manipulation evoked a following P3b that might reflect memory updating processes dependent on the behaviorally relevant stimulus (Polich, 2007).

As a final remark, we did not find a syntax-related early anterior negativity as is usually evoked by music-syntactic violations in the auditory domain (i.e., an ERAN; Koelsch, 2009; Koelsch, Gunter, Friederici, \& Schröger, 2000) and as was found in our previous study, in which chord progressions were presented as videos (Sammler, Novembre, et al., 2013). This suggests that the early anterior negativities might be specifically tied (i) to the auditory detection of music-syntactic irregularities (but see Gunter, Schmidt, \& Besson, 2003) and/or (ii) to the perceptual continuity of the musical input as present in dynamic auditory and video streams but less so in discrete photo series. The comparison of music-syntactic processing in perception and production and the potential beneficial effect of real motion on harmonic priming are interesting topics for future research.

\section{Conclusion}

In line with the notion of action hierarchy, we distinguished syntax-related motor programs operating at high levels of action planning from lower levels of specific movement selection. Using a priming paradigm involving the execution of chord progressions, we showed that expert pianists make motor predictions concerning the musical goal (Syntax) rather than the manner of execution (Manner). Building on previous findings (Sammler, Novembre, et al., 2013; Novembre \& Keller, 2011), our results provide further evidence for motor planning 
based on long-term music-syntactic knowledge (i.e., a grammar of action based on musical harmony) and for the priority of the motor plan related to the distal goal over the specific ways to achieve it. Although our EEG data do not give specific information on the generators underlying syntax and manner processing, their different electrophysiological and behavioral patterns may indicate different mechanisms in the planning of the musical goal and the movement used to achieve it. We suggest that, during production of musical sequences, motor predictions of the musical goal are driven by the harmonic structure of the musical context recognized through internalized syntactic knowledge of pianists. Critically, given a certain predictable context, the motor program of the distal musical goal might operate at high levels of the action control hierarchy and be incrementally translated to lower levels of movement kinematics at the very late stage of motor preparation. This weighing of action features (i.e., a weak, thus flexible, preselection of the optimal movement associated to the goal) would constitute an advantage in terms of more efficient performance and interactions with unexpected external changes. Finally, the notion that, through years of intensive motor practice, syntactic rules are motorically acquired, that is, a translation of musical syntax into a "grammar of action," might speak for a training-dependent motor plasticity toward an emergent syntax-based motor control. Whether this phenomenon occurs in other human actions associated with syntactic structures, such as speech, is an intriguing prospect for future investigations.

\section{Acknowledgments}

We are grateful to the pianists who participated in this experiment and to B. Pace who lent his hand for the stimulus preparation. We also thank S. Gutekunst for technical support. This research was funded by Max Planck Society.

Reprint requests should be sent to Roberta Bianco, Max Planck Institute for Human Cognitive and Brain Sciences, Stephanstraße 1a, 04103 Leipzig, Germany, or via e-mail: bianco@cbs.mpg.de.

\section{REFERENCES}

Aglioti, S. M., Cesari, P., Romani, M., \& Urgesi, C. (2008). Action anticipation and motor resonance in elite basketball players. Nature Neuroscience, 11, 1109-1116.

Bekkering, H., Wohlschläger, A., \& Gattis, M. (2000). Imitation of gestures in children is goal-directed. Quarterly Journal of Experimental Psychology, 53, 153-164.

Bortz, J. J., \& Doering, N. (2003). Forschungsmethoden und Evaluation: Fuer Human- und Sozialwissenschaftler. Berlin: Springer.

Bubic, A., von Cramon, D. Y., \& Schubotz, R. I. (2010). Prediction, cognition and the brain. Frontiers in Human Neuroscience, 4, 25.

Calvo-Merino, B., Glaser, D. E., Grèzes, J., Passingham, R. E., \& Haggard, P. (2005). Action observation and acquired motor skills: An fMRI study with expert dancers. Cerebral Cortex, $15,1243-1249$.

Cattaneo, L., Caruana, F., Jezzini, A., \& Rizzolatti, G. (2009). Representation of goal and movements without overt motor behavior in the human motor cortex: A transcranial magnetic stimulation study. Journal of Neuroscience, 29, 11134-11138.

Chaminade, T., Meltzoff, A. N., \& Decety, J. (2002). Does the end justify the means? A PET exploration of the mechanisms involved in human imitation. Neuroimage, 15, 318-328.

Clarke, E., Parncutt, R., Raekallio, M., \& Sloboda, J. (1997). Talking fingers: An interview study of pianists' views on fingering. Musicae Scientiae, 1, 87-107.

Clerget, E., Winderickx, A., Fadiga, L., \& Olivier, E. (2009). Role of Broca's area in encoding sequential human actions: A virtual lesion study. NeuroReport, 20, 1496-1499.

Cunnington, R., Windischberger, C., Deecke, L., \& Moser, E. (2003). The preparation and readiness for voluntary movement: A high-field event-related fMRI study of the Bereitschafts-BOLD response. Neuroimage, 20, 404-412.

Delorme, A., \& Makeig, S. (2004). EEGLAB: An open source toolbox for analysis of single-trial EEG dynamics including independent component analysis. Journal of Neuroscience Methods, 134, 9-21.

Drost, U. C., Rieger, M., Brass, M., Gunter, T. C., \& Prinz, W. (2005). When hearing turns into playing: Movement induction by auditory stimuli in pianists. Quarterly Journal of Experimental Psychology Section A, 58, 1376-1389.

Duncan-Johnson, C. C., \& Donchin, E. (1977). On quantifying surprise: The variation of event-related potentials with subjective probability. Psychophysiology, 14, 456-467.

Duncan-Johnson, C. C., \& Donchin, E. (1982). The P300 component of the event-related brain potential as an index of information processing. Biological Psychology, 14, 1-52.

Fadiga, L., Craighero, L., \& D'Ausilio, A. (2009). Broca's area in language, action, and music. Annals of the New York Academy of Sciences, 1169, 448-458.

Fazio, P., Cantagallo, A., Craighero, L., D’Ausilio, A., Roy, A. C., Pozzo, T., et al. (2009). Encoding of human action in Broca's area. Brain, 132, 1980-1988.

Fedorenko, E., Patel, A., Casasanto, D., Winawer, J., \& Gibson, E. (2009). Structural integration in language and music: Evidence for a shared system. Memory \& Cognition, 37, 1-9.

Fitch, W. T., \& Martins, M. D. (2014). Hierarchical processing in music, language, and action: Lashley revisited. Annals of the New York Academy of Sciences, 1316, 87-104.

Friederici, A. D. (2011). The brain basis of language processing: From structure to function. Physiological Reviews, 91, $1357-1392$.

Gellrich, M., \& Parncutt, R. (1998). Piano technique and fingering in the eighteenth and nineteenth centuries: Bringing a forgotten method back to life. British Journal of Music Education, 15, 5-23.

Gómez, C. M., Flores, A., Digiacomo, M. R., Ledesma, A., \& González-Rosa, J. (2008). P3a and P3b components associated to the neurocognitive evaluation of invalidly cued targets. Neuroscience Letters, 430, 181-185.

Grafton, S. T. (2009). Embodied cognition and the simulation of action to understand others. Annals of the New York Academy of Sciences, 1156, 97-117.

Grafton, S. T., \& Hamilton, A. F. D. C. (2007). Evidence for a distributed hierarchy of action representation in the brain. Human Movement Science, 26, 590-616.

Guerra-Filho, G., \& Aloimonos, Y. (2012). The syntax of human actions and interactions. Journal of Neurolinguistics, 25, 500-514.

Gunter, T. C., Schmidt, B. H., \& Besson, M. (2003). Let's face the music: A behavioral and electrophysiological 
exploration of score reading. Psychophysiology, 40 , 742-751.

Haggard, P. (2008). Human volition: Towards a neuroscience of will. Nature Reviews Neuroscience, 9, 934-946.

Hamilton, A. F. D. C., \& Grafton, S. T. (2006). Goal representation in human anterior intraparietal sulcus. Journal of Neuroscience, 26, 1133-1137.

Hauser, M. D., Chomsky, N., \& Fitch, W. T. (2002). The faculty of language: What is it, who has it, and how did it evolve? Science, 298, 1569-1579.

Hund-Georgiadis, M., \& von Cramon, D. Y. (1999). Motorlearning-related changes in piano players and non-musicians revealed by functional magnetic-resonance signals. Experimental Brain Research, 125, 417-425.

Katz, J., \& Pesetsky, D. (2011). The identity thesis of language and music. ling.auf.net/lingBuzz/000959.

Keele, S. W., \& Summers, J. J. (1976). The structure of motor programs. In G. E. Stelmach (Ed.), Motor control: Issues and trends (pp. 109-142). New York: Academic Press.

Keller, P. E. (2012). What movement force reveals about cognitive processes in music performance. In A. Mornell (Ed.), Art in motion II (pp. 115-153). Frankfurt, Germany: Peter Lang

Koelsch, S. (2005). Neural substrates of processing syntax and semantics in music. Current Opinion in Neurobiology, 15, 207-212.

Koelsch, S. (2009). Music-syntactic processing and auditory memory: Similarities and differences between ERAN and MMN. Psychophysiology, 46, 179-190.

Koelsch, S., Gunter, T., Friederici, A. D., \& Schröger, E. (2000). Brain indices of music processing: "Nonmusicians" are musical. Journal of Cognitive Neuroscience, 12, 520-541.

Koelsch, S., Gunther, T. C., Wittfoth, M., \& Sammler, D. (2005). Interaction between syntax processing in language and in music: An ERP study. Journal of Cognitive Neuroscience, 17, $1565-1577$.

Koeneke, S., Lutz, K., Herwig, U., Ziemann, U., \& Jäncke, L. (2006). Extensive training of elementary finger tapping movements changes the pattern of motor cortex excitability. Experimental Brain Research, 174, 199-209.

Koski, L., Wohlschläger, A., Bekkering, H., Woods, R. P., Dubeau, M.-C., Mazziotta, J. C., et al. (2002). Modulation of motor and premotor activity during imitation of targetdirected actions. Cerebral Cortex, 12, 847-855.

Lago, A., \& Fernandez-del-Olmo, M. (2011). Movement observation specifies motor programs activated by the action observed objective. Neuroscience Letters, 493, 102-106.

Lashley, K. (1951). The problem of serial order in behavior. In L. A. Jeffress (Ed.), Cerebral mechanisms in behavior (pp. 112-131). New York: Wiley.

Leuthold, H., \& Jentzsch, I. (2002). Spatiotemporal source localisation reveals involvement of medial premotor areas in movement reprogramming. Experimental Brain Research, 144, 178-188.

Maess, B., Koelsch, S., Gunter, T. C., \& Friederici, A. D. (2001). Musical syntax is processed in Broca's area: An MEG study. Nature Neuroscience, 4, 540-545.

Michel, C. M., Murray, M. M., Lantz, G., Gonzalez, S., Spinelli, L., \& Grave de Peralta, R. (2004). EEG source imaging. Clinical Neurophysiology, 115, 2195-2222.

Moro, A. (2014a). On the similarity between syntax and actions. Trends in Cognitive Sciences, 18, 109-110.

Moro, A. (2014b). Response to Pulvermuller: The syntax of actions and other metaphors. Trends in Cognitive Sciences, 18, 221.

Novembre, G., \& Keller, P. E. (2011). A grammar of action generates predictions in skilled musicians. Consciousness and Cognition, 20, 1232-1243.
Palmer, C., \& Meyer, R. K. (2000). Conceptual and motor learning in music performance. Psychological Science, 11, 63-68.

Palmer, C., \& Pfordresher, P. Q. (2003). Incremental planning in sequence production. Psychological Review, 110, 683-712.

Pastra, K., \& Aloimonos, Y. (2012). The minimalist grammar of action. Philosophical Transactions of the Royal Society of London, Series B, Biological Sciences, 367, 103-117.

Patel, A. D. (2003). Language, music, syntax and the brain Nature Neuroscience, 6, 674-681.

Patel, A. D., Gibson, E., Ratner, J., Besson, M., \& Holcomb, P. J. (1998). Processing syntactic relations in language and music: An event-related potential study. Journal of Cognitive Neuroscience, 10, 717-733.

Perruchet, P., \& Pacton, S. (2006). Implicit learning and statistical learning: One phenomenon, two approaches. Trends in Cognitive Sciences, 10, 233-238.

Polich, J. (2007). Updating P300: An integrative theory of P3a and P3b. Clinical Neurophysiology, 118, 2128-2148.

Pulvermüller, F. (2014). The syntax of action. Trends in Cognitive Sciences, 18, 219-220.

Pulvermüller, F., \& Fadiga, L. (2010). Active perception: Sensorimotor circuits as a cortical basis for language. Nature Reviews Neuroscience, 11, 351-360.

Rektor, I (2000). Parallel information processing in motor systems: Intracerebral recordings of readiness potential and CNV in human subjects. Neural Plasticity, 7 , $65-72$.

Rohrmeier, M. (2011). Towards a generative syntax of tonal harmony. Journal of Mathematics and Music, 5, 35-53.

Rohrmeier, M. A., \& Koelsch, S. (2012). Predictive information processing in music cognition. A critical review. International Journal of Psychophysiology, 83, 164-175.

Rosenbaum, D. A., Kenny, S. B., \& Derr, M. A. (1983). Hierarchical control of rapid movement sequences. Journal of Experimental Psychology: Human Perception and Performance, 9, 86-102.

Sammler, D., Koelsch, S., Ball, T., Brandt, A., Grigutsch, M., Huppertz, H. J., et al. (2013). Co-localizing linguistic and musical syntax with intracranial EEG. Neuroimage, 64, 134-146.

Sammler, D., Koelsch, S., \& Friederici, A. D. (2011). Are left fronto-temporal brain areas a prerequisite for normal music-syntactic processing? Cortex, 47, 659-673.

Sammler, D., Novembre, G., Koelsch, S., \& Keller, P. E. (2013). Syntax in a pianist's hand: ERP signatures of "embodied" syntax processing in music. Cortex, 49, $1325-1339$.

Schmidt, R. A. (1975). A schema theory of discrete motor skill learning. Psychological Review, 82, 225-260.

Shaffer, L. H. (1981). Performances of Chopin, Bach, and Bartok: Studies in motor programming. Cognitive Psychology, 13, 326-376.

Sharbrough, F., Chatrian, G.-E., Lesser, R. P., Lueders, H., Nuwer, M., \& Picton, T. W. (1991). American Electroencephalographic Society guidelines for standard electrode position nomenclature. Journal of Clinical Neurophysiology, 8, 200-202.

Slevc, L. R., Rosenberg, J. C., \& Patel, A. D. (2009). Making psycholinguistics musical: Self-paced reading time evidence for shared processing of linguistic and musical syntax. Psychonomic Bulletin \& Review, 16, 374-381.

Sloboda, J. A., Clarke, E. F., Parncutt, R., \& Raekallio, M. (1998). Determinants of finger choice in piano sight-reading. Journal of Experimental Psychology: Human Perception and Performance, 24, 185-203. 
Smith, J. L., Johnstone, S. J., \& Barry, R. J. (2006). Effects of pre-stimulus processing on subsequent events in a warned go/nogo paradigm: Response preparation, execution and inhibition. International Journal of Psychophysiology, 61, 121-133.

Summers, J. J., \& Anson, J. G. (2009). Current status of the motor program: Revisited. Human Movement Science, 28, 566-577.

Tenenbaum, J. B., Kemp, C., Griffiths, T. L., \& Goodman, N. D. (2011). How to grow a mind: Statistics, structure, and abstraction. Science, 331, 1279-1285.

Tillmann, B. (2012). Music and language perception: Expectations, structural integration, and cognitive sequencing. Topics in Cognitive Science, 4, 568-584.
Uithol, S., van Rooij, I., Bekkering, H., \& Haselager, P. (2012). Hierarchies in action and motor control. Journal of Cognitive Neuroscience, 24, 1077-1086.

Walter, W. G., Cooper, R., Aldridge, V. J., MacCallum, W. C., \& Winter, A. L. (1964). Contingent negative variation: An electric sign of sensori-motor association and expectancy in the human brain. Nature, 203, 380-384.

Wilson, M., \& Knoblich, G. (2005). The case for motor involvement in perceiving conspecifics. Psychological Bulletin, 131, 460-473.

Wohlschläger, A., Gattis, M., \& Bekkering, H. (2003). Action generation and action perception in imitation: An instance of the ideomotor principle. Philosophical Transactions of the Royal Society of London, Series B, Biological Sciences, 358, 501-515. 